\title{
$\mathrm{SPH}$ 법을 이용한 해안에서의 2차원 비선형파 수치시율레이션
}

\author{
김 철호*, 이영길 ${ }^{\dagger \star *}$, 정 광 열* \\ 인하대학교 대학원 조선해양공학과* \\ 인하대학교 기계공학부 조선해양공학전공 ${ }^{\star *}$
}

\section{Numerical Simulation of Two-dimensional Nonlinear Waves on Beaches Using a Smoothed Particle Hydrodynamics Method}

\author{
Cheol-Ho Kim", Young-Gill Lee ${ }^{\dagger \star \star}$ and Kwang-Leol Jeong*
}

Dept. of Naval Architecture and Ocean Engineering, Graduate School of Inha University, Incheon, Korea*

Dept. of Naval Architecture and Ocean Engineering, Inha University, Incheon, Korea**

\begin{abstract}
In this paper, wave breakers which occur in two dimensional coasts are simulated using a SPH(Smoothed Particle Hydrodynamics) method which represents the movement of fluidic physical volume with particles. As continuative fluid is approximated to the particles, the simulations are performed using fully Lagrangian method without any grid system. Two-dimensional Navier-Stokes equations and continuity equation are used for the numerical simulations. To generate incident waves, a piston type wavemaker is employed. The accuracy of the wave which is numerically generated by the wavemaker is verified by comparing with analytical results. The computations are carried out with various wave heights and slopes. The wave patterns generated through the numerical simulations are compared with several existing experimental and computational results. Agreement between the experimental data and the computation results is comparatively good. Also, the breaker depth index and the breaker height index from the present calculations are compared with the existing experimental results, and the tendency is very similar.
\end{abstract}

※Keywords: Wave breaker(쇄파), Lagrangian method(라그랑지안법), Smoothed Particle Hydrodynamics(SPH), Wavemaker(조파기), Two-dimensional coast(2차원 해안)

접수일: 2010년 1월 27일, 승인일: 2010년 7월 2일

1.서 론

†교신저자: younglee@inha.ac.kr, 032-860-7340

선박공학 및 해양공학의 유체역학분야를 특징지 
을 수 있는 것 중의 하나는 자유수면이 존재한다는 것이다. 특히, 이러한 자유수면은 대부분 비선형적 인 현상을 동반하므로, 이에 대한 취급법은 오랜 기간 동안 중요한 연구대상이 되어 왔다. 이러한 비선형 자유수면 현상을 시뮬레이션하기 위하여 전산유체역학분야에 있어서는 MAC(Marker And Cell)법(Welch et al., 1966)이 고안되었다. MAC법 은 자유수면에 가상의 점들을 띄워 놓게 되며, 이 러한 가상의 점들을 매 시간단계마다 이동 시키는 방법에 의하여 자유수면의 변화를 표현할 수 있게 된다. 그 후 VOF(Volume Of Fluid)법(Hirt and Nichols, 1981) 및 밀도함수법(Park and Miyata, 1994)은 MAC법으로 계산 불가능한 쇄파현상을 계 산 가능하도록 하였다. Lee and $\mathrm{HeO}(2005)$ 는 밀 도함수법을 이용하여 2차원 해안에서 발생하는 쇄 파현상을 수치시율레이션 하였다.

MAC법, VOF법, 밀도함수법 등은 고정된 오 일러리언(Eulerian) 격자계에서 Navier-Stokes 방정식을 풀게 된다. 이러한 방법에서는 수치 확산이 유발되고, 자유 수면의 변형이 매우 큰 경우 수치 확산은 더욱 커지게 된다. 한편 입자 를 사용하는 PIC(Particle In Cell)법, PIC법의 개량인 FLIP(Fluid Implicit Particle)법(Brackbill and Ruppel, 1986), SPH(Smoothed Particle Hydrodynamics)법(Monaghan, 1988), MPS(Moving Particle Semi-implicit)법(Koshizuka and Oka, 1996) 등은 격자생성의 복잡한 작업이 불필요하 며, 경계면이 크게 변형되는 문제에도 적용될 수 있는 수치시뮬레이션 기법이다. 입자를 이용 한 수치시율레이션 방법은, 비선형 자유수면 유 동 수치시뮬레이션의 경우에 있어서, 격자를 이 용한 해석방법보다 복잡한 형상의 물리현상에 유리하다. 또한 입자를 이용한 수치시뮬레이션 방법은 대류항의 계산을 입자의 이동으로 계산 함으로써 오일러리언(Eulerian) 방법에서 유발되 는 수치 확산을 줄일 수 있다(Lee et al., 2007). 초기 SPH법은 천체 물리학(Astrophysics) 계산 을 위해 개발되었지만(Lucy, 1977; Gingold and Monaghan, 1977), 후에 유체역학 및 구조해석 등 다양한 분야의 문제들로 확장되었다. Monaghan (1994)은 자유수면 유동을 시뮬레이션 하기 위하
여 댐 붕괴 및 조파기를 이용하여 해안에서 파도의 전진과정을 시뮬레이션 하였다. Monaghan and Kos(1999)는 해변에서 고립파의 run-up현상과 천 수영역을 지나 수직벽에 의해 되돌아오는 고립파 의 전진과정을 실험 및 수치시뮬레이션 하였다. Gomez and Dalrymple(2004)은 댐 붕괴로 발생하 는 파도에 의하여 수직 구조물에 미치는 하중을 실 험결과와 비교하였다.

본 논문에서는 비압축성 유동의 수치시뮬레이션 을 위하여, Monaghan(1988)이 제안한 SPH법을 응용하여 해안에서 비선형 자유수면의 쇄파 문제 를 수치시뮬레이션 하였다. 해안에서의 쇄파문제는 파력, 해안침식, 퇴적물 이동 등에 중요한 정보를 제공하고 선박의 비선형 조파특성 등의 연구에 활 용가능 함으로 $\mathrm{SPH}$ 를 이용한 해안에서의 쇄파시 율레이션 결과를 Lee and $\mathrm{HeO}(2005)$ 가 유한차분 법을 이용하여 시율레이션 한 결과와 정량적, 정성 적으로 비교하여 그 적용가능성을 확인하였다.

\section{2. 수치기법}

$\mathrm{SPH}$ 법에서 유동은 이산화 된 유체입자로 해석 되며, 이산적으로 거치되어 있는 입자의 물리량 $f(x)$ 와 $\nabla \cdot f(x)$ 는 커널함수(Kernel function)를 활용하여 각각 식 (1), 식 (2)와 같이 분포함수로 기술될 수 있다.

$$
\begin{aligned}
& f(x)=\int_{\Omega} f\left(x^{\prime}\right) W\left(x-x^{\prime}, h\right) d x^{\prime} \\
& \nabla \cdot f(x) \cong \int_{\Omega} \nabla f\left(x^{\prime}\right) W\left(x-x^{\prime}, h\right) d x^{\prime}
\end{aligned}
$$

부분 적분을 수행하는 경우 식 (2)는 다음과 같 이 변환되며

$\nabla \cdot f(x) \cong-\int_{\Omega} f\left(x^{\prime}\right) \cdot \nabla W\left(x-x^{\prime}, h\right) d x^{\prime}$

$\mathrm{N}$ 개의 입자를 활용하여 식 (1)과 식 (2)를 이산 화 하면 다음과 같다.

$$
f\left(x_{i}\right)=\sum_{j=1}^{N} \frac{m_{j}}{\rho_{j}} f\left(x_{j}\right) W\left(x_{i}-x_{j}, h\right)
$$




$$
\nabla \cdot f\left(x_{i}\right)=-\sum_{j=1}^{N} \frac{m_{j}}{\rho_{j}} f\left(x_{j}\right) \cdot \nabla_{i} W\left(x_{i}-x_{j}, h\right)
$$

$W\left(x_{i}-x_{j}, h\right)$ 는 커널함수이고, $h$ 는 완화길이 (Smoothing length), $\Omega$ 는 입자간 상호작용 영역 을 나타내고, $i, j$ 는 입자, $m_{j}$ 그리고 $\rho_{j}$ 는 각각 질 량과 밀도를 나타낸다. 이산화 된 입자는 질량, 압 력, 운동량 그리고 밀도 등과 같은 물리량을 가진 다. 입자의 이동과 물리량 변화는 입자들 간의 상 호작용에 의하여 발생하며, 입자간의 상호작용은 커널함수에 의하여 정의되어진다. 본 연구에서 사 용한 커널함수는 Monaghan(1985)에 의하여 제안 된 Piecewise cubic spline 이다.

지배방정식으로는 2 차원의 연속방정식과 운동 량 방정식을 사용하였으며, 커널함수를 활용하여 이산화 된 연속방정식(식 (6))과 운동량 방정식(식 (7))을 표현하면 다음과 같다.

$$
\begin{aligned}
& \frac{D \rho_{i}}{D t}=\sum_{j} m_{j}\left(u_{i}-u_{j}\right) \cdot \nabla_{i} W_{i j} \\
& \frac{D u_{i}}{D t}=-\sum_{j} m_{j}\left(\frac{p_{i}}{\rho_{i}^{2}}+\frac{p_{j}}{\rho_{j}^{2}}+\Pi_{i j}\right) \nabla_{i} W_{i j}+F_{i}
\end{aligned}
$$

위 식의 $W_{i j}=W\left(x_{i}-x_{j}, h\right)$ 는 커널함수, $u_{i}, u_{j}$ 와 $x_{i}, x_{j}$ 는 각각 $i, j$ 입자의 속도와 위치, $F_{i}$ 는 체적 력, $\nabla_{i}$ 는 $i$ 입자의 위치에서 커널의 구배를 나타 낸다.

유체역학 분야에서 일반적으로 물과 같은 액체 를 비압축성 유체로 가정하여 계산하나, SPH법에 서는 압축성이 있는 유체로 가정하여 계산한다. Batchelor(1967)와 Monaghan(1994)은 인공 압축 성(Artificial compressibility)이라는 개념을 적용하 여 압력을 상태방정식(식 (8))로부터 계산하였으 며, 본 연구에서도 동일한 방법을 적용하였다.

$p_{i}=B\left[\left(\frac{\rho_{i}}{\rho_{0}}\right)^{7}-1\right]$

위 식에서 $B=c^{2} \rho_{0} / 7, \rho_{0}=1000 \mathrm{~kg} / \mathrm{m}^{3}$ 이고, $c$ 는 실제 음속이지만, 유체의 유동계산의 안정성을 높 이기 위하여 $c \approx 10 u_{\max }$ 로 수정하였다. $u_{\max }$ 는 유
체 입자의 최대 속도이다.

운동량 방정식으로 부터 얻어지는 속도로 입자 들이 이동하는 경우, 입자의 속도 분포가 불연속 적으로 나타나는 경우가 발생하게 된다. 입자의 속도분포를 연속적으로 유지하기 위하여 주위 입 자들의 속도와 커널함수를 이용하는 XSPH기법을 사용하였다(Wit, 2006).

점성 응력 항은 속도의 2계 미분으로 직접 계 산할 수 있으나 본 연구에서 사용된 커널함수의 2 계 미분 값은 상호작용하는 입자 사이의 거리 $r$ 에 대하여 선형적이고, $r_{i j}=2 / 3 h$ 에서 부호가 바 뀌게 된다. 이것은 때때로 운동량이 낮은 속도의 입자에서 높은 속도의 입자로 전해지는 비 물리적 인 현상이 발생할 수 있다. 이러한 현상을 방지하 기 위하여, 점성항을 직접 계산 하지 않고, 식 (9) 와 같은 인공 점성(Artificial viscosity)으로 모델링 하였다. 이런 모델링은 입자 사이의 거리와 관계 없이 높은 속도의 입자에서 낮은 속도의 입자로 운동량을 전해준다(Wit, 2006).

$\Pi_{i j}= \begin{cases}-\frac{\alpha h c}{\overline{\rho_{i j}}} \frac{u_{i j} \cdot r_{i j}}{r^{2_{i j}}+\varphi^{2}} & u_{i j} \cdot r_{i j}<0 \\ 0 & u_{i j} \cdot r_{i j} \geq 0\end{cases}$

위 식의 $\alpha$ 는 상수 $(0.01<\alpha<1), \overline{\rho_{i j}}=\left(\rho_{i}+\rho_{j}\right) / 2$ 는 평균 밀도이며, $u_{i j}=u_{i}-u_{j}, r_{i j}=r_{i}-r_{j}$ 이다. $\varphi=0.1 h_{i j}$ 는 두 입자사이의 거리가 0 이 될 때 발 생할 수 있는 특이성을 방지하기 위해 사용된다. 또한, 입자들끼리 덩어리를 형성하는 인장 불안정 성(Tensile instability)을 방지하기 위해서 인공압 력을 사용하였다(Monaghan, 2000).

경계조건(Boundary conditions)으로 유체 입자 가 물체 경계 입자를 관통하는 것을 방지하기 위 해 Lennard-Jones form을 사용하였으며 (Monaghan, 1994) 경계면으로부터 입자가 받는 영향을 최소화하기 위해 고스트 입자(Ghost particles)를 사용하였다(Fig. 1). 고스트 입자는 경계 입자를 기준으로 유체 입자의 위치가 입자간 의 상호작용 영역인 $\kappa h$ 범위에 들어오면 유체 입 자와 대칭 위치에 생성된다. 생성된 고스트 입자 는 유체 입자와 같은 밀도, 압력을 가지지만 속도 
는 반대 방향으로 작용함으로써 경계면에서 유체 입자의 수직한 방향의 속도와 수평한 방향의 속도 를 0 으로 만들어준다.

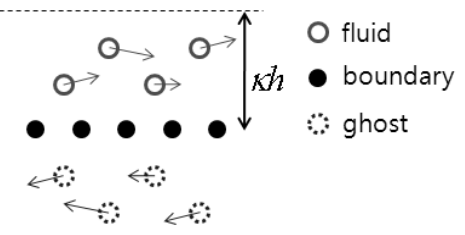

Fig. 1 Definition sketch for body boundary condition using ghost particles

\section{3. 계산 조건}

$\mathrm{SPH} H$ 법을 이용하여 다양한 특성을 가지는 쇄파 현상을 시뮬레이션 하여 정도를 검증하고 활용가 능성을 확인하였다. 2차원 피스톤 타입의 조파기 를 이용하여 파도를 생성하였으며, 피스톤의 운동 은 Hughes(1993)의 방법을 따랐다(식 (10)).

$X_{0}(t)=\frac{H}{2 m_{1}} \sin \sigma t+\frac{H^{2}}{32 d}\left(\frac{3 \cosh k d}{\sinh ^{3} k d}-\frac{2}{m_{1}}\right) \sin 2 \sigma t$

with

$m_{1}=\frac{4 \sinh ^{2} k d}{\sinh 2 k d+2 k d}$

위 식의 $k$ 는 파수, $d$ 는 수심이고, $H$ 는 파고, $\sigma$ 는 원 주파수이다.

Fig. 2는 시뮬레이션 하기 위한 계산 영역을 보 여준다. 수치시뮬레이션에 사용된 파도의 조건을 Table 1에 나타내었다. Fig. 3은 offshore parameter의 임계값에 근거한(Galvin, 1968) 쇄파 대 상사계수(Surf similarity parameter)(Battjes, 1974)에 따른 spilling과 plunging 쇄파의 영역을 보여준다. 파도는 쇄파대 상사계수에 따라 쇄파의 파정이 전복하는 plunging $\left(0.5<\xi_{0}<3.3\right)$ 과 쇄파의 파정이 전복하지 않는 spilling $\left(\xi_{0}<0.5\right)$ 영역으로 나뉜다. 쇄파대 상사계수는 식 (11)과 같이 정의 된다.

$$
\xi=\frac{m}{\left(H_{0} / L_{0}\right)^{1 / 2}}
$$

위 식의 $m$ 은 해안의 기울기, $H_{0}$ 는 입사파의 파 고이고, $L_{0}$ 는 입사파의 파장이다.

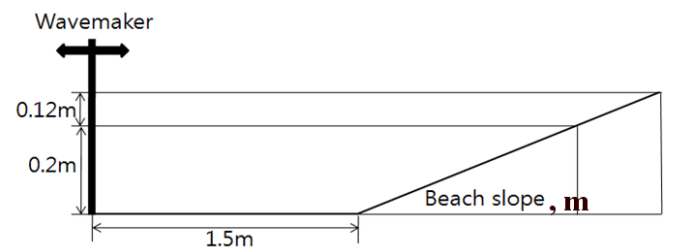

Fig. 2 Schematic of computational domain for wave breaking simulations on beach

Table 1 Conditions of incident waves

\begin{tabular}{|c|c|c|c|c|c|c|}
\hline Case & $\begin{array}{c}\text { Beach } \\
\text { slope, } \\
m\end{array}$ & $\begin{array}{c}T(s) \\
\text { Period, }\end{array}$ & $\begin{array}{c}\text { Wave } \\
\text { height, } \\
H_{0}(m)\end{array}$ & $\begin{array}{c}\text { Wave } \\
\text { length, } \\
L_{0}(m)\end{array}$ & $\begin{array}{c}\text { Wave } \\
\text { steepness } \\
, H_{0} / L_{0}\end{array}$ & $\begin{array}{c}\text { Surf } \\
\text { similarity } \\
\text { parameter } \\
, \xi_{0}\end{array}$ \\
\hline 1 & $1 / 5$ & 0.80 & 0.060 & 1.000 & 0.060 & 0.816 \\
\hline 2 & $1 / 5$ & 0.80 & 0.100 & 1.000 & 0.100 & 0.632 \\
\hline 3 & $1 / 10$ & 0.80 & 0.080 & 1.000 & 0.080 & 0.354 \\
\hline
\end{tabular}

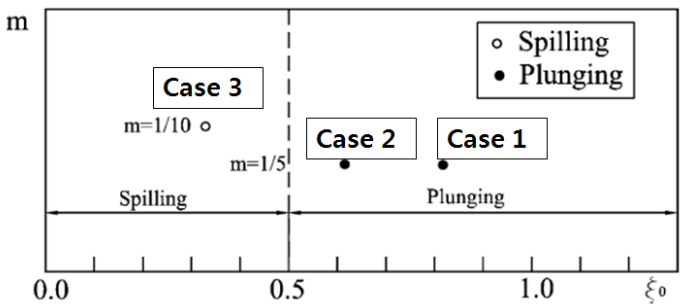

Fig. 3 Breaker type classification at each of the present computations.

\section{4. 계산 결과}

조파기로부터 생성되어 진행하는 파도의 정도를 검증하기 위하여 Case 3에서 해안을 없애고 수치 시율레이션을 수행하였다.

Fig. 4에서는 피스톤 타입의 조파기를 이용하여 생성한 파도의 파형과 2차 Stokes 파도의 이론적 파형을 비교하였다. 파도가 처음 생성될 때에는 조파기의 영향으로 2차 Stokes 파도와 생성된 파 


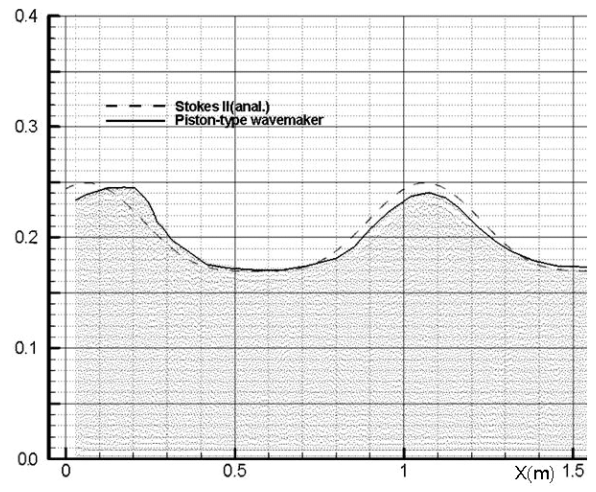

Fig. 4 Comparison of wave profiles $\left(H_{0}=\right.$ $0.080 \mathrm{~m}, \quad T=0.80 \mathrm{~s}$ )

도의 위상차가 나타나지만, 조파기로부터 멀어지 면서 파도의 위상차가 작아졌다. 또한 파도가 발 달한 후에 2차 Stokes 파도와 비교하였을 때, 파 고에 있어서 작은 차이를 보였다. 이는 $\mathrm{SPH} H$ 법에 서 유체는 약간의 압축성이 있다고 고려하므로 수 치시뮬레이션 초기에 자유수면의 하강현상이 발생 하기 때문이라고 여겨진다. 그러나 조파기를 이용 하여 생성한 파도의 파형과 2차 Stokes 파도의 파형에 있어서 큰 차이가 없다는 것을 확인하였 다.

Case 1의 경우와 Case 2의 경우, Hino et al.(1984)의 실험결과 그리고 Lee and $\mathrm{Heo}(2005)$ 가 밀도함수법을 이용하여 plunging 쇄파 영역에 서 수행한 수치계산결과를 SPH법을 이용한 수치 계산결과와 비교하였다(Fig. 5, Fig. 6). Case 3의 경우, Lee and $\mathrm{Heo}(2005)$ 가 밀도함수법을 이용 하여 spilling 쇄파 영역에서 수행한 수치계산결과 와 SPH법을 이용한 수치계산결과를 비교하였다 (Fig. 7).

Case 1의 경우, plunging 쇄파가 시뮬레이션 되었다. 파도가 해안의 경사면으로 들어오면서 위 상차가 발생했으나 파고를 비롯한 전체적인 경향 은 유사하다. Lee and $\mathrm{Heo(2005)의} \mathrm{계산결과와}$ 본 연구의 계산결과를 비교하면 해안의 경사면으 로 진입하기 전에는 파고 및 위상에 근접한 결과 가 나타나다가 해안의 경사면으로 진입하면서 약 간의 위상차를 보이고 있다.

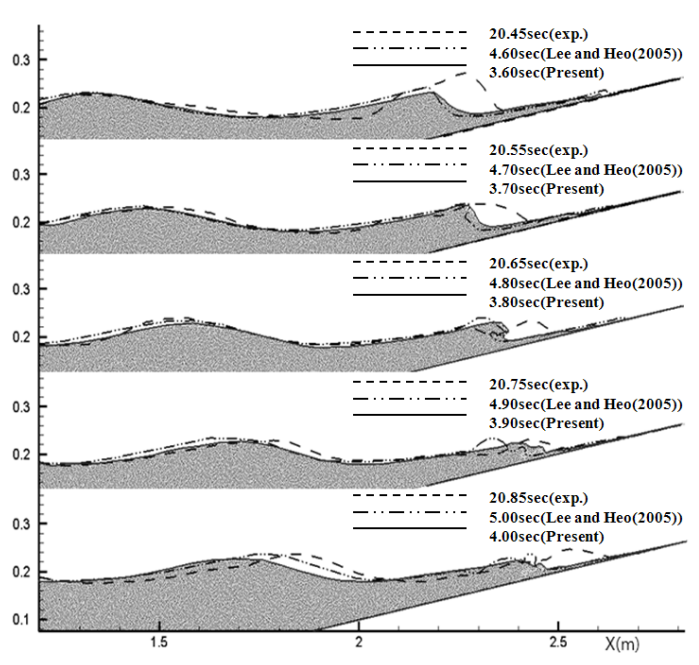

Fig. 5 Comparison of free surface profiles (Case 1)

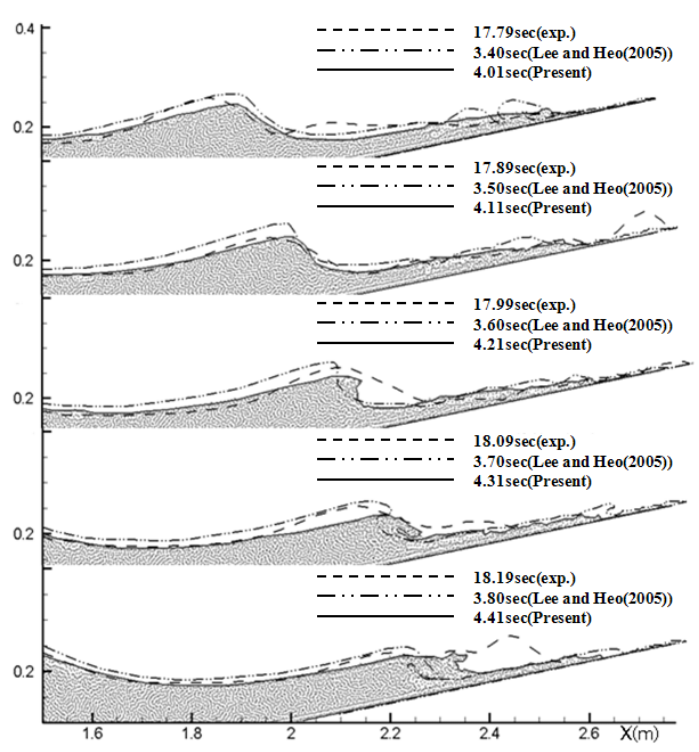

Fig. 6 Comparison of free surface profiles (Case 2)

Case 2의 경우, Battjes(1974)의 연구에 따르 면 쇄파대 상사계수의 값은 $0.632(\mathrm{Fig} .3$ ) 로 plunging 쇄파가 발생될 것으로 예상된다. 시뮬레이션결과 파도의 전복이 발생하는 plunging 쇄파가 시률레이션 되었음을 볼 수 있다. 또한 전 


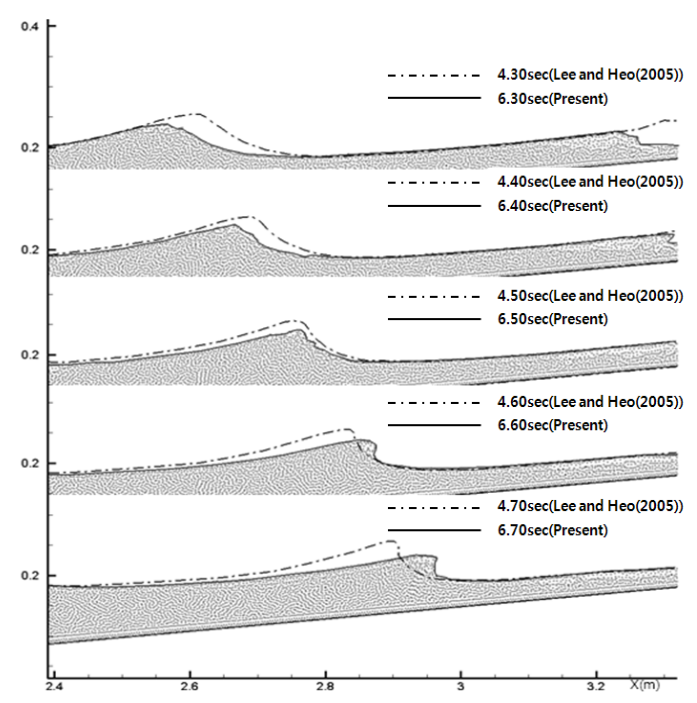

Fig. 7 Comparison of free surface profiles (Case 3)

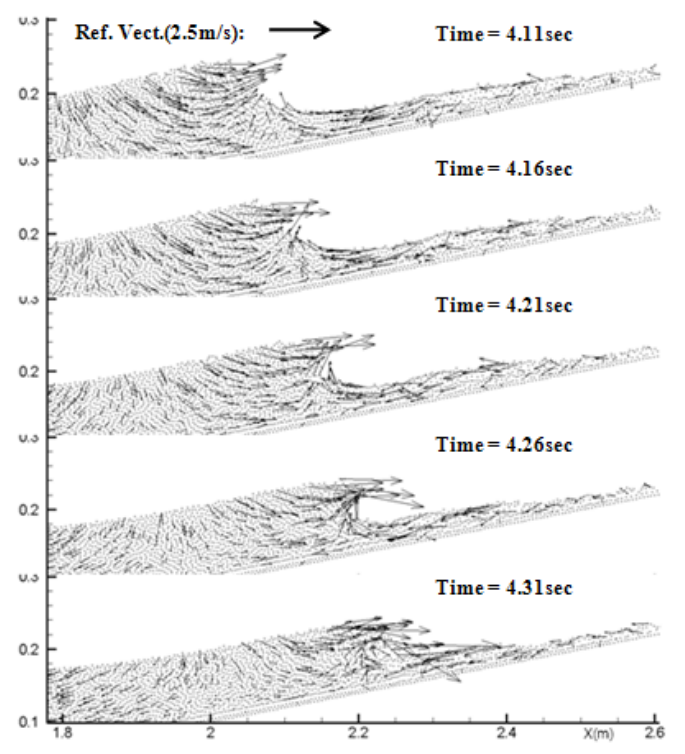

Fig. 8 Variation of velocity vectors with an advancing breaker (Case 2)

복된 jet가 자유수면과 다시 만난 후에 해안으로 솟아오르는(Run-up) 현상이 시율레이션 되었다.

Case 1 그리고 Case 2의 경우, 실험결과와 본 연구의 수치계산결과를 비교하면, 해안의 경사면 으로 진입 후 파고에 있어서 차이를 보이지만 근
접한 쇄파 지점(Breaker point)을 보임으로써 해안 에서의 쇄파 전진과정의 경향이 유사한 것으로 판 단된다.

Case 2와 Case 3의 경우, Lee and $\mathrm{Heo}(2005)$ 의 계산결과와 본 연구의 수치계산결과를 비교하 였을 때, 본 계산에서 파고가 낮게 나타났으며, Lee and $\mathrm{Heo}(2005)$ 의 계산결과보다 쇄파현상이 좀 더 일찍 일어나지만 전체적으로 유사한 경향을 보였다.

Case 1, 2 그리고 3의 경우, 파도가 해안으로 진입한 후에, 일도함수법을 이용한 Lee and HeO (2005)의 수치계산결과와 차이를 보이는 것은 SPH 법은 물과 같은 유체를 약간의 압축성을 지닌다고 고려하여 상태방정식(식 (8))으로부터 압력을 계산 하기 때문이다.

Fig. 8에서는 Case 2의 경우에 대하여 파도의 전진과정에 따른 속도벡터 변화를 보여주고 있다. 전복이 시작 되면서 파정에서 속도 벡터의 크기가 가장 큰 것을 확인하였다.

Fig. 9와 Fig. 10은 각각 breaker depth index 그리고 breaker height index 이다. 각각의 인덱스 는 식 (12), 식 (13)과 같이 정의한다.

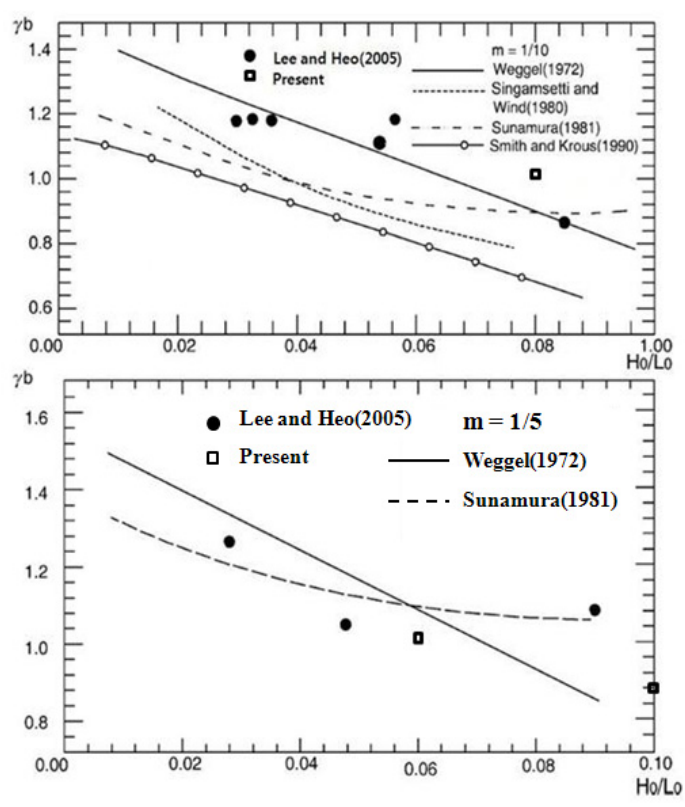

Fig. 9 Breaker depth indexes. 


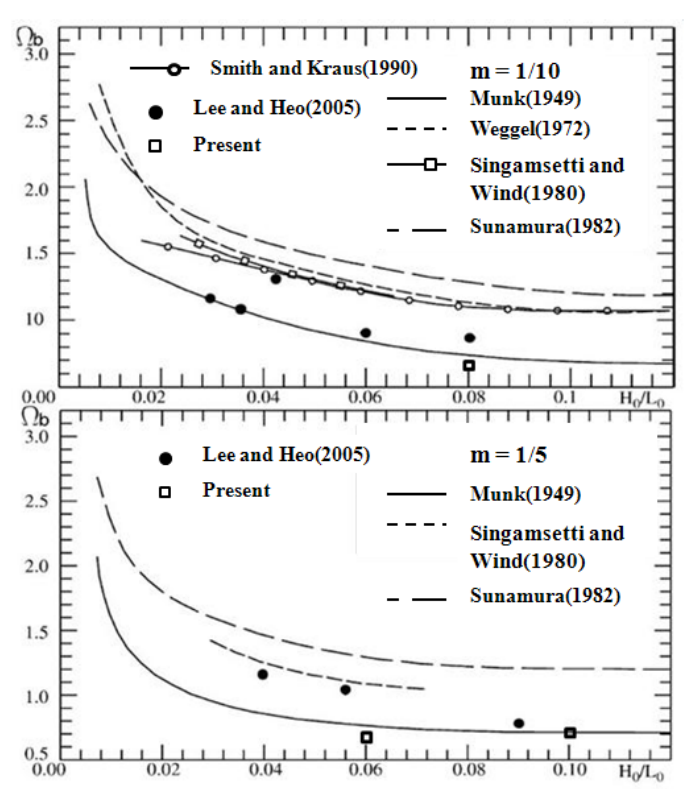

Fig. 10 Breaker height indexes.

$\gamma_{b}=\frac{H_{b}}{h_{b}} \quad$ The breaker depth index

$\Omega_{b}=\frac{H_{b}}{H_{0}} \quad$ The breaker height index

$H_{b}$ 와 $h_{b}$ 는 쇄파현상이 일어나는 지점에서 파도 의 높이, 깊이이다. 쇄파 지점은 Smith and Kraus(1990)가 채택했던 정의를 그대로 사용하였 다. 본 연구의 수치계산결과는 Weggel(1972) 그리 고 Munk(1949)의 실험결과와 경향이 유사한 것을 확인하였지만, 약간의 차이를 보이고 있다. 이러한 차이를 보이는 이유는 쇄파지점을 정의하는데 있 어서 판단 기준에 차이가 있고 또한 본 연구에서 생성된 파도의 파고가 약간 낮게 생성되었으며, 압력을 상태방정식(식 (8))으로부터 얻기 때문이라 고 여겨진다(Smith and Kraus, 1990).

\section{4. 결론}

본 논문은 해안에서 일어나는 비선형 쇄파현상 을 SPH법을 이용하여 수치시률레이션 하였다. 피 스톤 타입의 조파기를 이용하여 생성한 파도는 2차
Stokes 파도의 이론적 파형과 비교하여 정도를 검 증하였고, 파고와 파형의 큰 차이가 없다는 것을 확인하였다.

이를 2차원 해안에 적용하여 spilling 파도와 두 번째 plunging jet를 포함하는 plunging 파도의 전 진과정에 대한 수치시뮬레이션을 수행하였다. 본 논문의 수치계산결과를 Hino et al.(1984)의 실험 결과 그리고 밀도함수법을 이용한 Lee and $\mathrm{HeO}$ (2005)의 수치계산결과와 비교하였다. 연속적인 유 체를 입자들로 근사시키는 방법으로 정량적, 정성 적으로 좋은 결과를 확인할 수 있었다.

그러나 해안의 경사면으로 파도가 진입하기 전 에는 Hino et al.(1984)의 실험결과 그리고 Lee and $\mathrm{HeO}$ (2005)의 수치계산결과와 근접한 파도의 위상을 보이지만, 파고는 약간의 차이를 보였다. 이러한 차이는 $\mathrm{SPH}$ 법은 물과 같은 유체를 약간의 압축성을 지닌다고 고려하여 압력을 상태방정식으 로 계산하기 때문이다. 파도가 경사면 진입 후 Hino et al.(1984)의 실험결과와 비교하였을 때, 파고는 낮지만 근접한 쇄파지점을 보이며 쇄파현 상이 일어난 후의 전진과정 또한 유사하다. 또한, Lee and $\mathrm{HeO}(2005)$ 의 수치계산결과와 비교하였 을 때, 본 계산의 결과는 전체적으로 파고가 낮게 나타났으며 쇄파현상이 좀 더 일찍 일어나지만 전 체적인 경향은 유사하다. 수치계산결과의 breaker depth index와 breaker height index를 기존의 실 험결과들과 비교하여 쇄파지점에 대한 경향이 유 사함을 확인하였다.

$\mathrm{SPH} H$ 법은 특히 쇄파와 같은 비선형 자유수면 현 상을 지닌 실질적인 공학 문제에 쉽게 적용할 수 있을 것으로 판단된다. 좀 더 정도 높은 결과를 얻기 위하여 수치적인 감쇠현상을 줄이기 위한 수 치기법의 개발이 필요하다. 또한 압력을 상태방정 식으로 계산함으로써 발생하는 오차를 줄이기 위 한 수치기법의 개선이 필요하다.

\section{후 기}

이 논문은 2008년도 정부(교육과학기술부)의 재원으로 한국과학재단의 지원을 받아 수행된 연 구임(No. R01-2008-000-20531-0). 


\section{참 고 문 헌}

- Batchelor, G.K., 1967, An Introduction to Fluid Dynamics, Cambridge University Press.

- Galvin, C.J., 1968, "Breaker Type Classification on Three Laboratory Beaches," Journal of Geophysical Research 73.

- Gomez-Gesteira, M. and Dalrymple, R.A., 2004, "Using a Three-Dimensional Smoothed Particle Hydrodynamics Method for Wave Impact on a Tall Structure," Journal of Waterway, Port, Coastal and Ocean Engineering, Vol. 130, No. 2, pp. 63-69.

- Hino, T., Miyata, H., Kajitani, H. and Kanai, M., 1984, "A Numerical Solution Method for Nonlinear Shallow Water Waves (Second Report)," Journal of the Society of Naval Architecture of Japan, Vol. 154, pp. 29-39.

- Hughes, S.A., 1993, Physical Models and Laboratory Techniques in Coastal Engineering, World Scientific Publishing Co. Pte. Ltd. 7.4.1

- Lee, B.H., Park, J.C., Jeong, S.J., Ryu, M.C., Kim, Y.S. and Kim, Y.H., 2007, "Numerical Simulation of Non-linear Free-surface Motions Using Moving Particle Semi-implicit(MPS) Method", Journal of Ocean Engineering and Technology, Vol. 21, No. 6, pp 53-58.

- Lee, Y.G. and Heo, J.K., 2005, "Simulating Nonlinear Waves on the Free Surface in Surf Zones with Two-Dimensional Sloping Beach," Ocean Engineering, Vol. 32, pp. 57-84.

- Liu, G. and Liu, M., 2003, Smoothed Particle Hydrodynamics. World Scientific Publishing Co. Pte. Ltd. 3.3.1, 3.3.2, 5.
- Monaghan, J.J., 1988, "An Introduction to SPH," Computer Physics Communications, Vol. 48, pp. 89-96.

- Monaghan, J.J., 1992, "Smoothed Particle Hydrodynamics," Annual review of astronomy and astrophysics, 30, pp. 543-574.

- Monaghan, J.J., 1994, "Simulating Free Surface Flows with SPH," Journal of Computational Physics, 110, pp. 399-406.

- Monaghan, J.J., 2000, "SPH without a Tensile Instability," Journal of Computational Physics, 159, pp. 290-311.

- Monaghan, J.J. and Kos, A., 1999, "Solitary Waves on a Cretan Beach," Journal of Waterway, Port, Coastal, and Ocean Engineering, Vol. 125, pp. 145-154.

- Smith, E.R. and Kraus, N.C., 1990, "Laboratory Study on Macro-Features of Wave Breaking Over Bars and Artificial Reefs," Technical Report CERC-90-12, US Army Engr., WES, Vicksburg, Mississippi, pp. 307-323.

- Wit,L., 2006, "Smoothed Particle Hydrodynamics A Study of the possibilities of SPH in hydraulic engineering," MSc Thesis, Delft University of Technology.
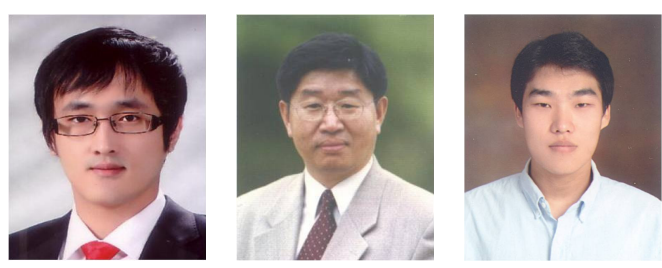

< 김 철 호 > 